\title{
Native Valve Endocarditis
}

National Cancer Institute

\section{Source}

National Cancer Institute. Native Valve Endocarditis. NCI Thesaurus. Code C128355.

Endocarditis affecting a native valve of the heart. 